\title{
29. A NOTE ON THE SPORADIC METEOR RADIANT DISTRIBUTION
}

\author{
L. Tř́śsová \\ (Geophysical Institute of the Czechoslovak Academy of Sciences, Prague)
}

Some results concerning the sporadic radiant distribution - or rather the sporadic radiant efficiency - obtained from meteor forward-scatter data are presented.

From the forward-scatter data when only one receiving antenna is used, it is not possible to determine the arrival direction of individual particles, but it is possible to determine the probability $P$ of signal reception for a given source position. This probability depends on the geometry of the path (length, direction, location of the midpoint), on the technical parameters (radiated power, sensitivity of the receiving apparatus, pattern of antennas, etc.) and on the mass distribution of meteoric particles. The technical parameters and geometrical properties of the path are known, the mass distribution is assumed.

If $n$ point sources are acting simultaneously, the echo rate $N$ is proportional to the sum

$$
N \sim \sum_{i=1}^{n} P_{i} M_{i}
$$

where $M_{i}$ is the source strength (number of particles from a given direction during a time unit on a unit surface). Assuming $M_{i}$ to be constant during 1 month and using for $N$ the average monthly echo rates for each hour, we obtain 24 equations in $n$ unknowns $M_{i}$. The $P_{i}$ are calculated and $N$ is determined experimentally. Using the least squares method, we are able to determine $M_{i}$ for each month.

The echo rates were obtained from a continuous 1-year observation on the path Sofia $\left(42^{\circ} 41^{\prime} \mathrm{N}, 23^{\circ} 22^{\prime} \mathrm{E}\right)$ - Panská Ves $\left(50^{\circ} 32^{\prime} \mathrm{N}, 14^{\circ} 34^{\prime} \mathrm{E}\right)$ made during 1965. Detailed description of the apparatus, measuring method, data evaluation and obtained results is given elsewhere (Třísková, 1966; Třísková and Samardžiev, 1967). The mass distribution of meteoric particles was assumed to be in the form

$$
P\{\mu \geqslant m\} \sim \frac{m^{1-s}}{s-1}, \quad s \approx 2 .
$$

Three models of radiant sources were investigated. For each model the simultaneous action of a uniform background and three point sources was assumed, one point source situated at the apex and two point sources in the ecliptic plane displaced (a) 
$\pm 50^{\circ}$, (b) $\pm 60^{\circ}$, (c) $\pm 70^{\circ}$ of ecliptic longitude from the apex. Results are summarized in Figures 1, 2 and 3.

Figure 1 shows the annual variation of the apex source strength for individual models. The least dispersion is seen for values obtained under the assumption of sources positioned according to (c), not only for the apex but also for the other sources. Thus this model was considered as the most satisfactory one.

For the model (c) the annual variations, of the strength of the sources relative to the March apex value are shown in Figure 2. Peaks in June for the helion source and in August for the apex and anti-helion sources occurred because the influence of strong showers was not completely eliminated, although the days with maximum shower

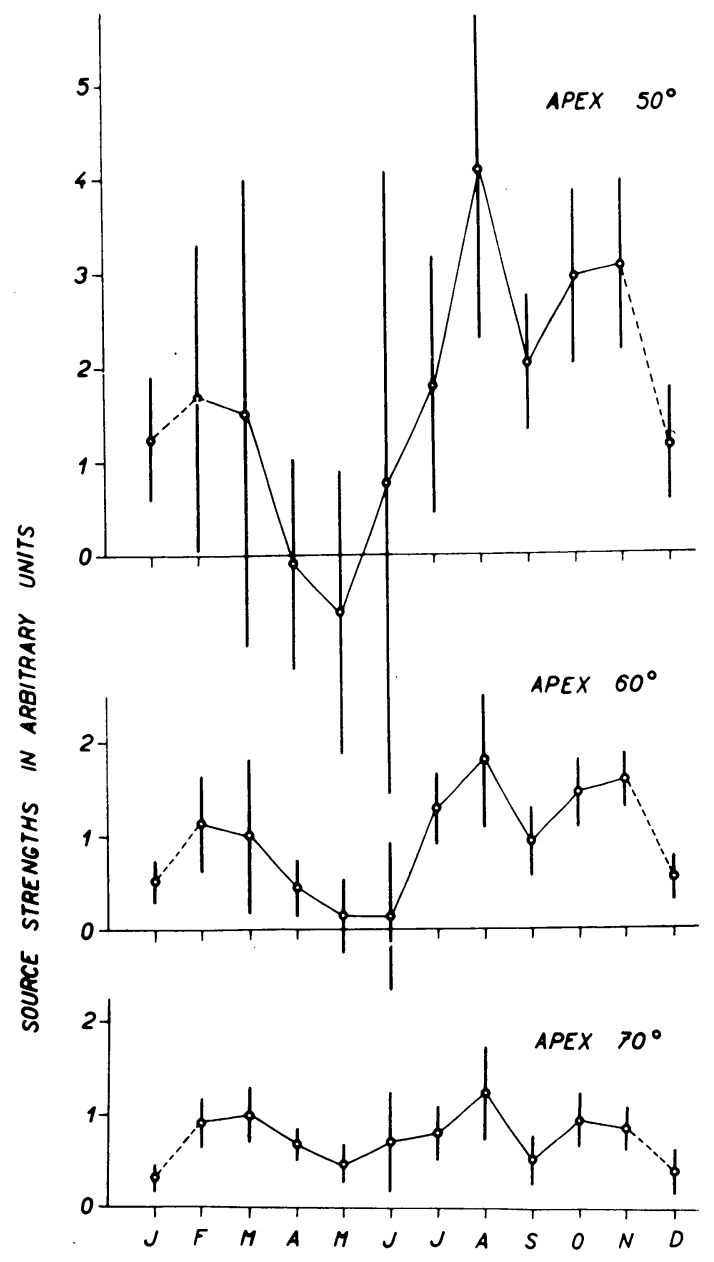

FIG. 1. 

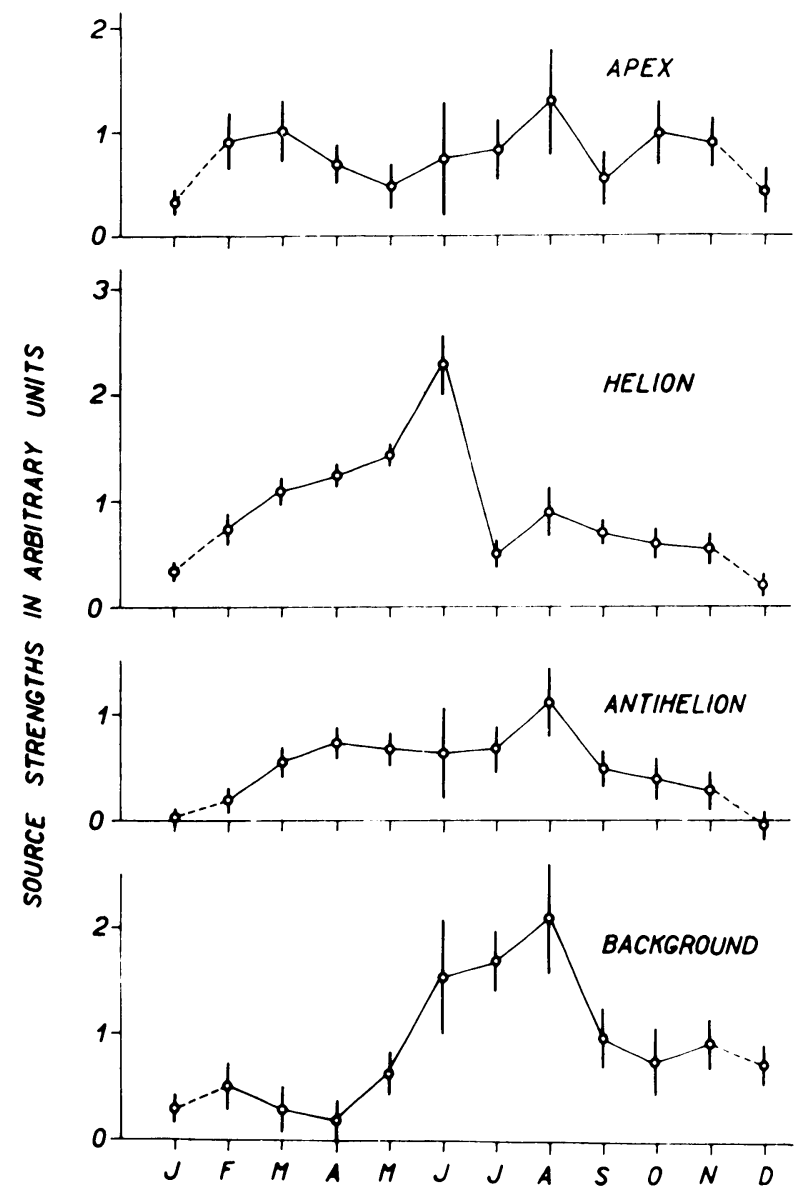

FIG. 2.

activity were not included in the average echo rates. The annual variation of the background shows the spring minimum and the general increase of meteoric activity in the second half of the year. The January and December values are smaller than the actual ones due to strongly reduced output of the transmitter.

The annual average values of source efficiency are shown on Figure 3 in comparison with the radiant distributions deduced from radar measurements (Hawkins, 1956; Davies, 1957). Making this comparison, it should be remembered that curves 1 and 2 followed from measurements of the arrival direction of particles, whereas our values resulted from comparison of calculated values for the effect of three point sources with statistically evaluated experimental data. The apex value was taken as the basic one. As can be seen, the efficiency ratio of the solar and apex source is in all cases nearly 


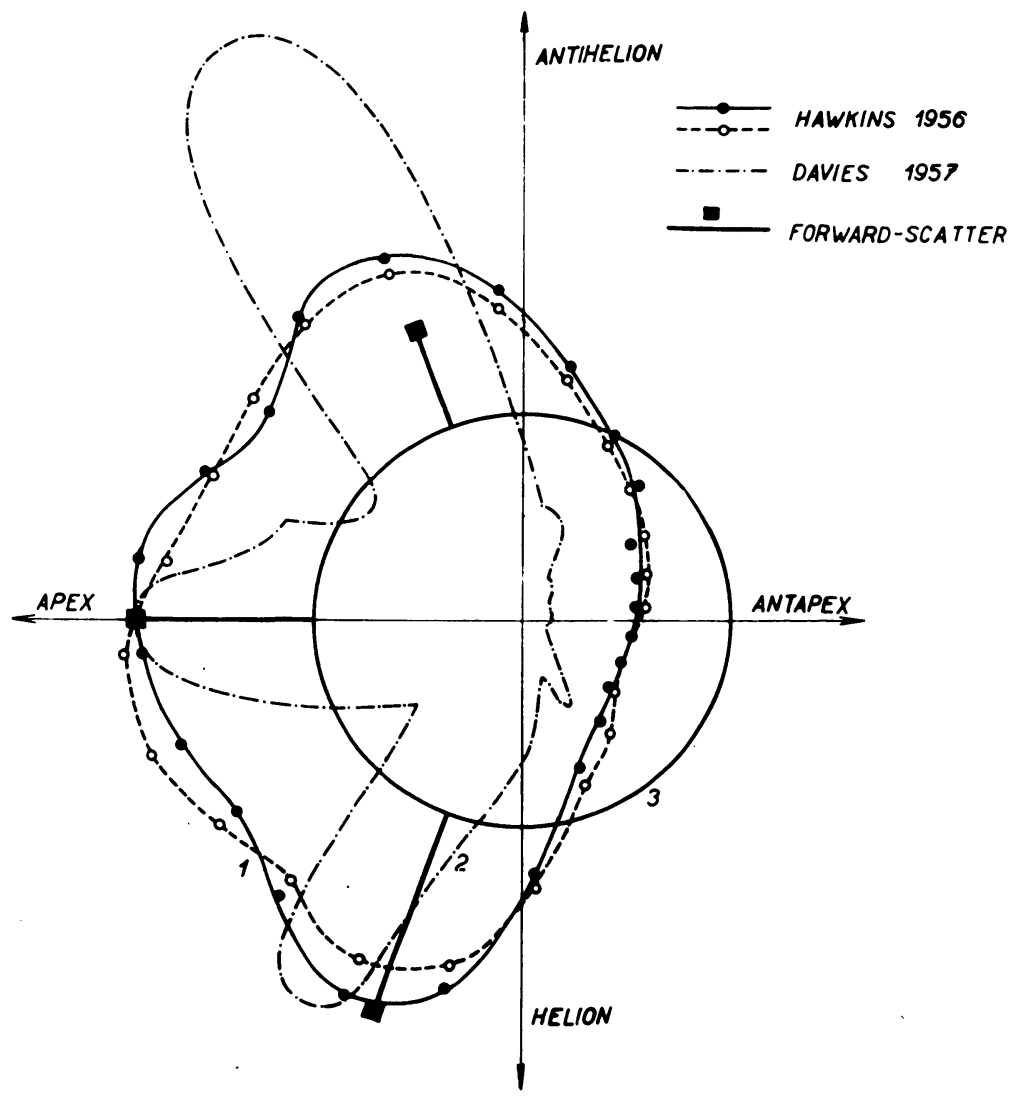

FIG. 3.

$1: 1$. Also the location of sources is generally in good agreement. Disagreement is seen as to the efficiency of the anti-solar source. Our ratio of the antihelion and apex-source strength 0.8 is more in accordance with results represented by the curve 1 .

The results described above do not constitute a determination of the real positions of the sporadic meteor radiants. Rather, a model of radiant distribution is suggested which effectively characterizes the sporadic meteor activity and can be used for a preliminary calculation of average hourly echo rates for given conditions.

\section{References}

Davies, J. G. (1957) Adv. Electronics Electron Phys., 9, 95.

Hawkins, G.S. (1956) Mon. Not. R. astr. Soc., 116, 92.

Třísková, L. (1966) Studia geoph. geod., 10, 475.

Třísková, L., Samardžiev, D. (1967) Geomagn. Aeronom., 7, 300. 